\title{
Bis-methyl imidazolium methylidene bis(trifluoromethanesulfonyl)imide, crystal structure, thermal and dielectric studies
}

\author{
BOUMEDIENE HADDAD ${ }^{1,2,3, *}$, TAQIYEDDINE MOUMENE ${ }^{2}$, DIDIER VILLEMIN ${ }^{1}$, \\ JEAN-FRANÇOIS LOHIER ${ }^{1}$ and EL-HABIB BELARBI ${ }^{2}$ \\ ${ }^{1}$ LCMT, ENSICAEN, UMR 6507 CNRS, Labex EMC3, University of Caen, 6 bd Ml Juin, 14050 Caen, France \\ ${ }^{2}$ Synthesis and Catalysis Laboratory LSCT, Tiaret University, Tiaret 14000, Algeria \\ ${ }^{3}$ Department of Chemistry, Dr Moulay Tahar University of Saida, Saida 20000, Algeria
}

MS received 2 June 2015; accepted 3 December 2015

\begin{abstract}
A new geminal di-cationic ionic liquid (IL) containing a central cationic unit methylidene capped by a basic functionality (imidazole) is synthesized. The compound was characterized by means of ${ }^{1} \mathrm{H},{ }^{13} \mathrm{C},{ }^{19} \mathrm{~F}$ NMR, IR and Raman spectroscopies and its crystal structure is confirmed by single crystal $\mathrm{X}$-ray diffraction method. The X-ray studies on $\left(\left[\mathrm{M}\left(\mathrm{CH}_{2}\right) \mathrm{IM}^{2+}\right]\left[2 \mathrm{NTf}_{2}^{-}\right]\right)$show that it crystallizes in monoclinic system with space group: $P$ 21/c. Thermal properties were investigated in the temperature range from 0 to $400^{\circ} \mathrm{C}$ by using differential thermal (DTA) and thermogravimetric (TGA) analyses. The frequency-dependent electrical data are discussed using complex dielectric permittivity in the frequency range of $\left(10^{-2}-10^{6} \mathrm{~Hz}\right)$ and in the temperature range of $-50^{\circ}$ to $20^{\circ} \mathrm{C}$. The outstanding dielectric and thermal properties make this IL as promising candidate for electrochemical devices.
\end{abstract}

Keywords. Di-cationic ionic liquids; crystal structure; dielectric; thermal properties.

\section{Introduction}

The chemistry of ionic liquids (ILs) has been of interest for decades [1]. Recently new types of di-cationic attracted increasing attention from both industrial and academic fields. Compared to traditional monocationic, these di-cationic ILs are new structures characterized by the presence of a doubly charged cation that is composed of two singly charged cations linked by an alkyl chain and paired with two singly charged anions [2,3]. One of the most interesting features of ILs is that they have controllable physiochemical and solvation properties. Nowadays, they have been structurally exposed in various emerging areas as solvents of high temperature organic synthesis [4], additives in dye-sensitized solar cells [5], extraction liquids [6], in mass spectroscopy [7] and as electrolytes for secondary batteries [8] or as a gas chromatography stationary phase [9].

Nevertheless, a deep knowledge of physical-chemical properties, crystal structure and thermal behaviour of di-cationic ILs is necessary to find the unique and general features and control their properties. In addition, few experimental studies have been dedicated to illustrate the structures of di-cationic ILs [10]; however, crystal structure and thermal properties of bis-methyl imidazolium methylidene bis(trifluoromethanesulfonyl)imide have not been reported yet.

In this paper, the crystal structure of $\left(\left[\mathrm{M}\left(\mathrm{CH}_{2}\right) \mathrm{IM}^{2+}\right]\right.$ $\left[2 \mathrm{NTf}_{2}^{-}\right]$) was analysed by X-ray diffraction. In addition, the thermogravimetric (TGA) and differential thermal (DTA)

\footnotetext{
*Author for correspondence (haddadboumediene@yahoo.com)
}

analyses studies were carried out to investigate the thermal stability of the IL. The dielectric behaviour of $\left(\left[\mathrm{M}\left(\mathrm{CH}_{2}\right)\right.\right.$ $\left.\mathrm{IM}^{2+}\right]\left[2 \mathrm{NTf}_{2}^{-}\right]$) was investigated by measuring the dielectric constant as a function of frequency at temperatures ranging from -20 to $50^{\circ} \mathrm{C}$.

\section{Experimental}

In the present study, synthesis of bis-methyl imidazolium methylidene bis(trifluoromethanesulfonyl)imide ionic liquid is based on a metathesis reaction of freshly prepared iodide salts of the bis-methyl imidazolium methylidene cation and bis(trifluoromethylsulfonyl)imide as anions (see figure 1).

In summary, in a round bottom flask, 1-methylimidazole $(9.07 \mathrm{ml}, 100 \mathrm{mmol})$ and 1,2-diiodomethane $(5.07 \mathrm{ml}$, $50 \mathrm{mmol})$ were dissolved in toluene $(15 \mathrm{ml})$ and the mixture was stirred at $70^{\circ} \mathrm{C}$ for $5 \mathrm{~h}$. The reaction mixture was evaporated at reduced pressure and the product was washed repeatedly with diethyl ether $(5 \times 20 \mathrm{ml})$ to remove any excess diiodomethane unreacted reactant, then the solvent was removed and the product was dried under vacuum for $6 \mathrm{~h}$ to obtain a product with high purity. Finally, bis-methyl imidazolium methylidene iodide yellowish solid (13.20 g, $31.86 \mathrm{mmol}$ ) was obtained in $73 \%$ yield.

In the second step, $\left[\mathrm{M}\left(\mathrm{CH}_{2}\right) \mathrm{IM}^{2+}\right]\left[2 \mathrm{NTf}_{2}^{-}\right]$was prepared by anion exchange reaction from iodide to bis(trifluoromethanesulfonyl)imide which was carried out by mixing $\left[\mathrm{M}\left(\mathrm{CH}_{2}\right) \mathrm{IM}^{2+}\right]\left[2 \mathrm{I}^{-}\right]$and $\mathrm{LiNTf}_{2}$ in water at room temperature for $2 \mathrm{~h}$. The mixture consisted of two separate 


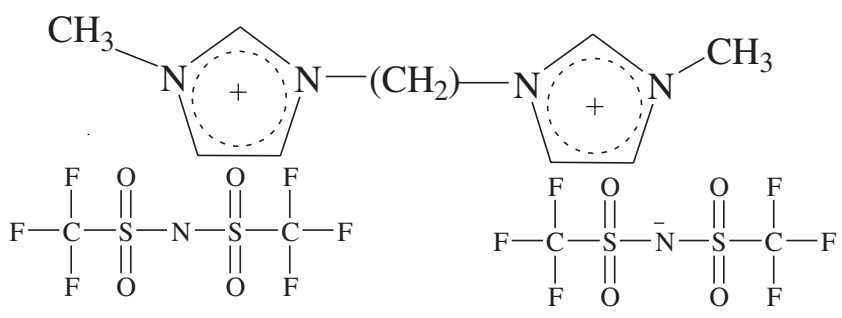

Figure 1. Structure of the new synthesized di-cationic ionic liquids.

phases: ionic liquid at the bottom and aqueous solution at the top. The former was separated from the latter by centrifugation $(3000 \mathrm{rpm})$ for $60 \mathrm{~s}$. The removal of residual volatile compounds from the ionic liquid was made in a vacuum using a rotary evaporator and then washed with fresh ethyl acetate $(100 \mathrm{ml})$.

To obtain high purity, the ionic liquid was washed under stirring using high-purity water to dissolve and remove water soluble impurities. Then, the two phases were separated and dried under constant agitation under vacuum conditions $(\approx 10 \mathrm{~Pa})$ at $70^{\circ} \mathrm{C}$ for several hours to reduce water content and volatile compounds. After isolation, the ionic liquid was dried in phosphorus pentoxide $\left(\mathrm{P}_{2} \mathrm{O}_{5}\right)$ to remove residual water.

Bis-methylimidazolium methylene bis(trifluromethanesulfonyl)imide is insoluble in water. The quantity of water determined by Karl Fischer titration (by using $831 \mathrm{KF}$ coulometer Metrohm with $703 \mathrm{Ti}$ Stand) of a solution of bismethylimidazolium methylene bis(trifluromethanesulfonyl)imide dissolved in the acetonitrile shows that there is $<0.1 \%$ of water in mass. Also, we have found no trace of iodine in bis-methylimidazolium methylene bis(trifluromethanesulfonyl)imide by elementary analysis. Iodine not detected $(<0.01 \%)$.

Structure of the obtained product was confirmed by using ${ }^{1} \mathrm{H},{ }^{13} \mathrm{C},{ }^{19} \mathrm{~F}$ NMR (DRX $400 \mathrm{MHz}$ spectrometer) and FTIR (Perkin-Elmer spectrum BX) spectroscopy to confirm the absence of any major impurities. Spectroscopic data are reported in our previous research [11] and given in the supporting information.

Crystals of $\left(\left[\mathrm{M}\left(\mathrm{CH}_{2}\right) \mathrm{IM}^{2+}\right]\left[2 \mathrm{NTf}_{2}^{-}\right]\right)$suitable for X-ray crystallography were obtained after recrystallization from a mixed DMF/ethylacetate (2:1) system. Data for crystal structure analysis were collected at $293 \mathrm{~K}$ with a Bruker-Nonius Kappa CCD area detector diffractometer with graphite monochromatized $\operatorname{MoK} \alpha$ radiation $(\lambda=$ $0.71073 \AA$ ). The structure was dissolved using direct methods and refined by full matrixleast-squares analysis on F2. TGA and DTA analyses were made on a NETZSCH STA $449 \mathrm{C}$ instrument in argon atmosphere, sample mass: 9 $\pm 0.001 \mathrm{mg}$; heating rate $5^{\circ} \mathrm{C} \mathrm{min}-1$, in the temperature range of $20-400^{\circ} \mathrm{C}$, temperature controller with an accuracy of $\pm 0.001{ }^{\circ} \mathrm{C}$ achieved in the entire range of measurements. The dielectric measurements were performed on pellets processed by applying uniaxial pressure on powder. Dielectric spectra were recorded by using BDS-4000 Novocontrol spectrometer, which was coupled with the

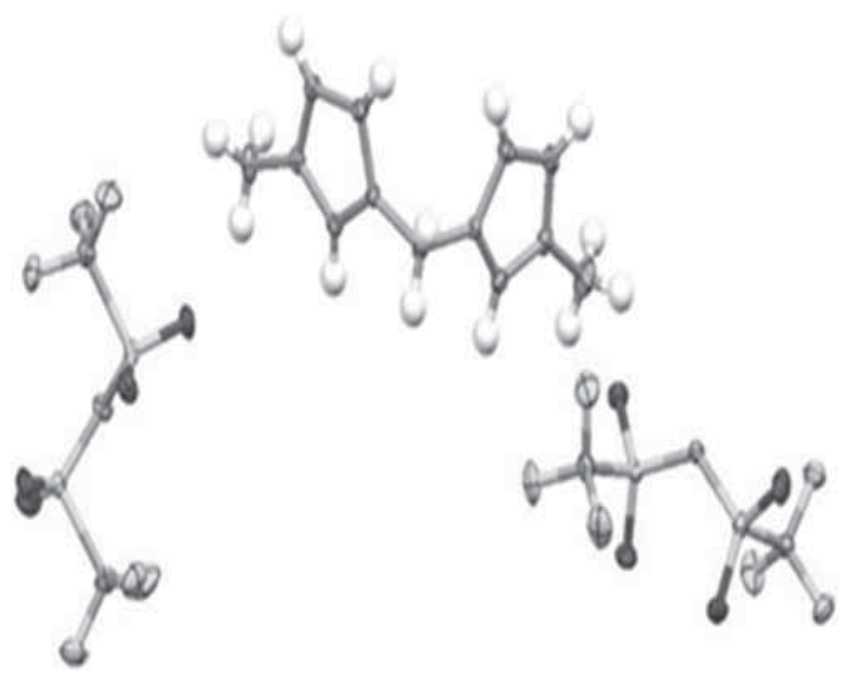

Figure 2. A view of the molecular structure of $\left(\left[\mathrm{M}\left(\mathrm{CH}_{2}\right) \mathrm{IM}^{2+}\right]\right.$ $\left.\left[2 \mathrm{NTf}_{2}^{-}\right]\right)$.

quarto system to ensure the temperature variation from -20 to $50 \pm 0.01^{\circ} \mathrm{C}$ in the frequency range $\left(10^{-2}-10^{6} \mathrm{~Hz}\right)$.

\section{Results and discussion}

\subsection{X-ray diffraction studies}

$\left(\left[\mathrm{M}\left(\mathrm{CH}_{2}\right) \mathrm{IM}^{2+}\right]\left[2 \mathrm{NTf}_{2}^{-}\right]\right)$(Crystallographic data (excluding structure factors) for $\left(\left[\mathrm{M}\left(\mathrm{CH}_{2}\right) \mathrm{IM}^{2+}\right]\left[2 \mathrm{NTf}_{2}^{-}\right]\right)$have been deposited with the Cambridge Crystallographic Data Centre as supplementary publication number CCDC1038876. These data can be obtained free of charge via www.ccdc.cam.ac.uk/data_request/cif, by emailing data_request@ccdc.cam.ac.uk, or by contacting The Cambridge Crystallographic Data Centre, 12 Union Road, Cambridge CB2 1EZ, UK; fax: 441223 336033) crystallizes in the monoclinic system, space group $\mathrm{P} 21 / \mathrm{c}$, with unit cell parameters $\mathrm{a}=10.1727$ (2) $\AA, \mathrm{b}=15.6134$ (3) $\AA, \mathrm{c}=$ 16.2269 (3) $\AA, \alpha=90^{\circ}, \beta=92.989(1)^{\circ}, \gamma=90^{\circ}, \mathrm{Z}=4$, $\mathrm{V}=2573.82(9) \AA^{3}, \mathrm{Dc}=1.906 \mathrm{~g} \mathrm{~cm}^{-3}, \mu=0.510 \mathrm{~mm}^{-1}$ and $\mathrm{F}(000)=1480.0$. The determination of the crystal structure at $100 \mathrm{~K}$ was carried out on a Nonius Kappa CCD diffractometer. Intensity data were collected by a $\omega-\varphi$ scan technique in the range of $2.39^{\circ}-32.06^{\circ}$ with index ranges as follows: $-14 \leq h \leq 15,-23 \leq k \leq 23,-24 \leq l \leq 24$. The programme for structure solution and refinement were SHELXS-97 [12] and SHELX-97 [13], respectively. The crystal structure of this compound is shown in figure 2.

We noticed that the $\mathrm{S}-\mathrm{O}$ bond length falls in the range of 1.4274 (9)-1.4368 (9) $\AA$ and the O2-S1-O1 angles fall in the range $117.81(6)^{\circ}-119.15(5)^{\circ}$. Symmetry code: (a) $\mathrm{x}, \mathrm{y}, \mathrm{z}$; (b) $-\mathrm{x}, \frac{1}{2}+\mathrm{y}, \frac{1}{2}-\mathrm{z}$; (c) $-\mathrm{x},-\mathrm{y},-\mathrm{z}$; (d) $\mathrm{x}, \frac{1}{2}-\mathrm{y}, \frac{1}{2}+\mathrm{z}$. It is observed that the $\left[\mathrm{NTf}_{2}^{-}\right]$anion in IL adopts the trans conformation with S1-N5-S2, S3-N5-S4 bond angles, 124.62(6) ${ }^{\circ}$; $125.32(6)^{\circ}$, respectively. Within the crystal, the packing is governed by many intermolecular weak interactions, six of 
$\mathrm{C}-\mathrm{H}$. . O type and one of $\mathrm{C}-\mathrm{H}$. . F type. Molecules are further linked together (or stabilized) by C-F... imidazolium ( $\pi$-ring) interactions (figure 3 ).

\subsection{Thermal decomposition studies}

TGA is a versatile tool for studying thermal stability of materials [14]. From figure $4 \mathrm{a}$ it can be suggested that the TGA curve of IL beyond $200^{\circ} \mathrm{C}$ show three decomposition ranges. The first range $\left(40-71^{\circ} \mathrm{C}\right)$ corresponds to a dehydration process and can probably be originated from minor water molecules impurity in the sample. Next step of the thermal decomposition in the temperature range $\left(253-320^{\circ} \mathrm{C}\right)$ corresponds to the decomposition of anion $\left[\mathrm{NTf}_{2}^{-}\right]$, while the decomposition of $\left[\mathrm{M}\left(\mathrm{CH}_{2}\right) \mathrm{IM}^{2+}\right]$ cation occurs from 350

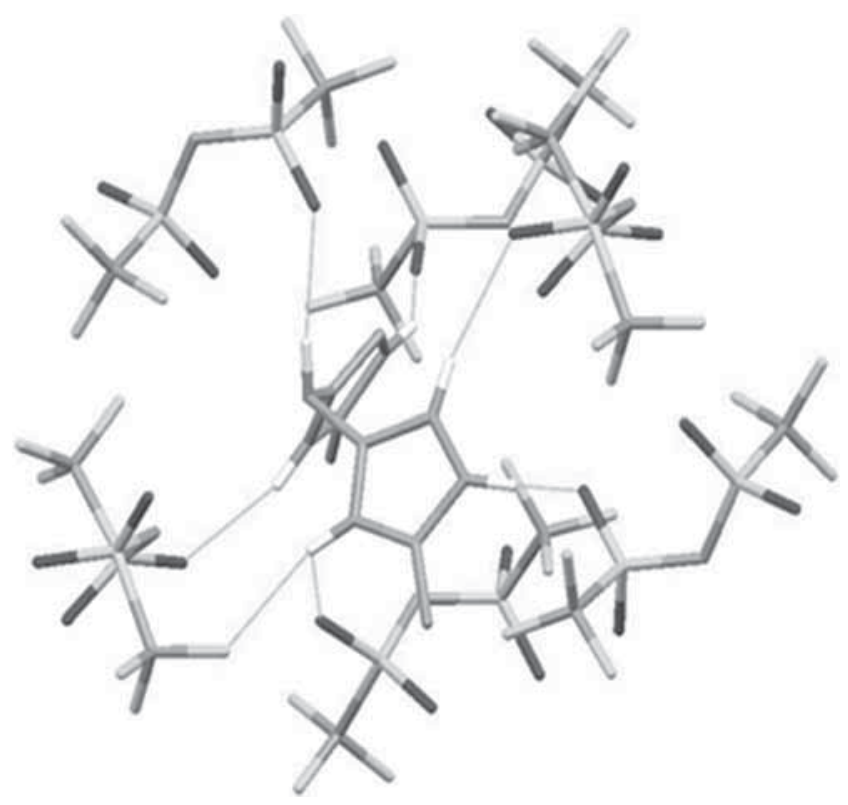

Figure 3. A view of crystal packing of $\left(\left[\mathrm{M}\left(\mathrm{CH}_{2}\right) \mathrm{IM}^{2+}\right]\left[2 \mathrm{NTf}_{2}^{-}\right]\right)$. to $400^{\circ} \mathrm{C}$ [15-17]. In our case, we considered the temperature corresponding to the second degradation step $\left(\mathrm{Td}_{2}\right)$ as the operational limit for the studied ionic liquid. However, according to previous reports by Seddon and group, the minimum and maximum values should be lowered by 75 and $100^{\circ} \mathrm{C}$, respectively $[18,19]$. In general, our ionic liquid show a thermal stability with respect to di-cationic pyrrolidinium and imidazolium salts having aliphatic spacers as previously reported by Anderson and co-workers [20]. The very different thermal stability could be a result of the different nature of the spacer used. However, alternatively in our case, TGA curve of IL indicates that the decompositions of this IL follow more than one-step degradation mechanism of which the second step at around $253^{\circ} \mathrm{C}$ which increases to $400^{\circ} \mathrm{C}$ in the third step corresponding to total degradation of IL, indicating that good thermal stability, which is adequate for the application of this IL as electrolyte for electrochemical devices [21].

Additionally, The experimental DTA data of $\left(\left[\mathrm{M}\left(\mathrm{CH}_{2}\right)\right.\right.$ $\left.\left.\mathrm{IM}^{2+}\right]\left[2 \mathrm{NTf}_{2}^{-}\right]\right)$are shown in figure $4 \mathrm{~b}$. The curve in the figure shows three endothermic peaks at $63,295^{\circ} \mathrm{C}$ and one broad peak at $400^{\circ} \mathrm{C}$. The first endothermic peak may be the melting point of the IL or corresponds to a dehydration process observed by using TGA. The second stage is associated with the thermal decomposition of anion $\left[\mathrm{NTf}_{2}^{-}\right]$in the temperature range of $253-320^{\circ} \mathrm{C}$ and the release next to $\left[\mathrm{M}\left(\mathrm{CH}_{2}\right) \mathrm{IM}^{2+}\right]$ cation in the temperature range $350-400^{\circ} \mathrm{C}$, respectively. The DTA study exactly fits and confirms the TGA study.

\subsection{Permittivity measurements}

The frequency dependence of the real $\varepsilon^{\prime}(\omega)$ and the imaginary $\varepsilon^{\prime \prime}(\omega)$ parts of the permittivity for $\left(\left[\mathrm{M}\left(\mathrm{CH}_{2}\right) \mathrm{IM}^{2+}\right]\right.$ $\left.\left[2 \mathrm{NTf}_{2}^{-}\right]\right)$, at various temperatures are shown in figure $5 \mathrm{a}$ and $b$, respectively. The real part of the dielectric function $\varepsilon^{\prime}$ turns from the high frequency limit to the static value $\varepsilon_{\mathrm{S}}$

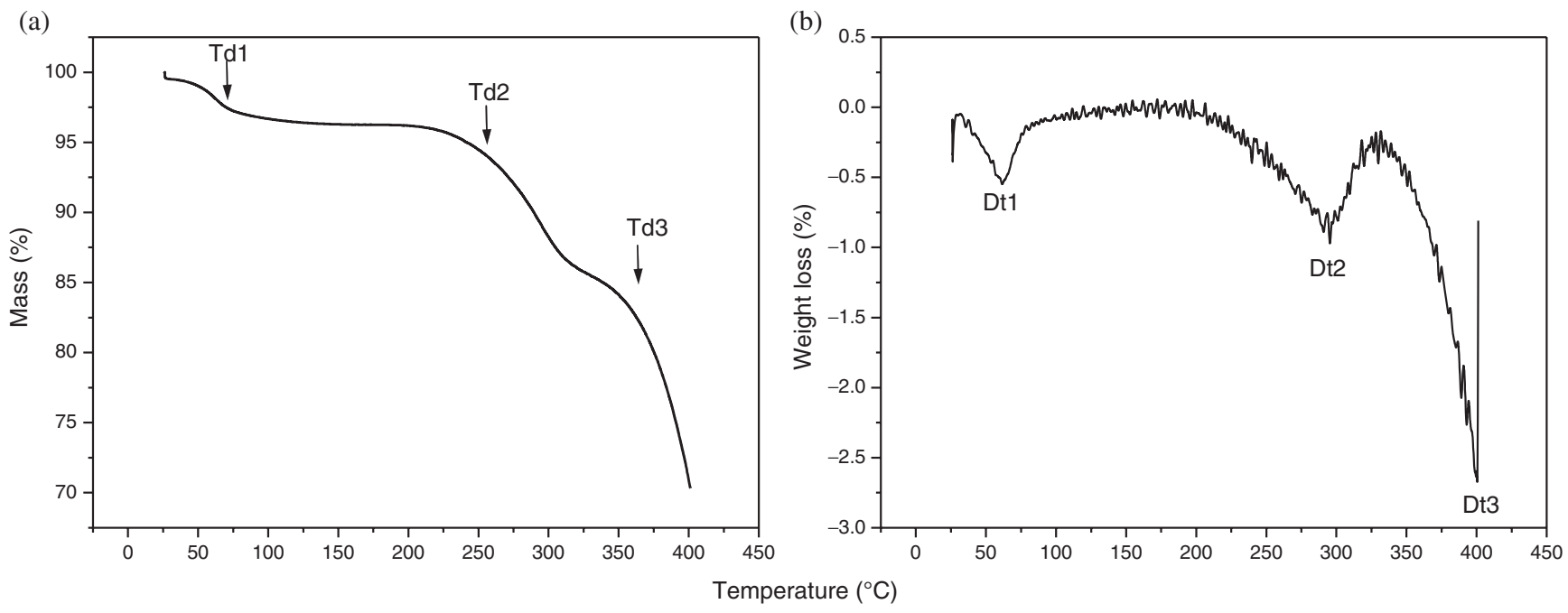

Figure 4. (a and b) TG-DTA curves of $\left(\left[\mathrm{M}\left(\mathrm{CH}_{2}\right) \mathrm{IM}^{2+}\right]\left[2 \mathrm{NTf}_{2}^{-}\right]\right)$. 
(a)

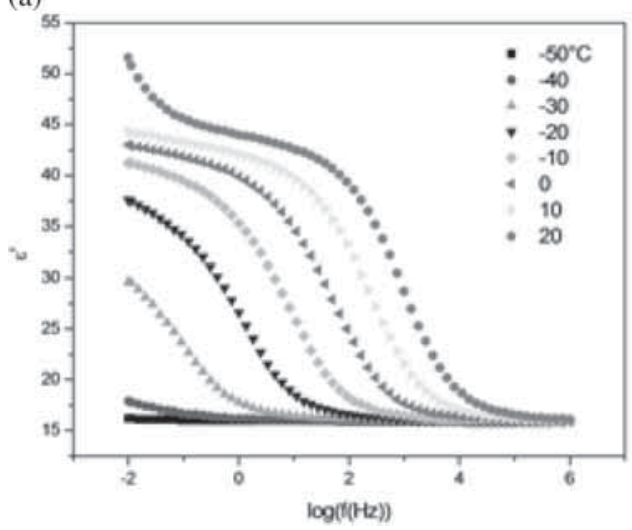

(b)

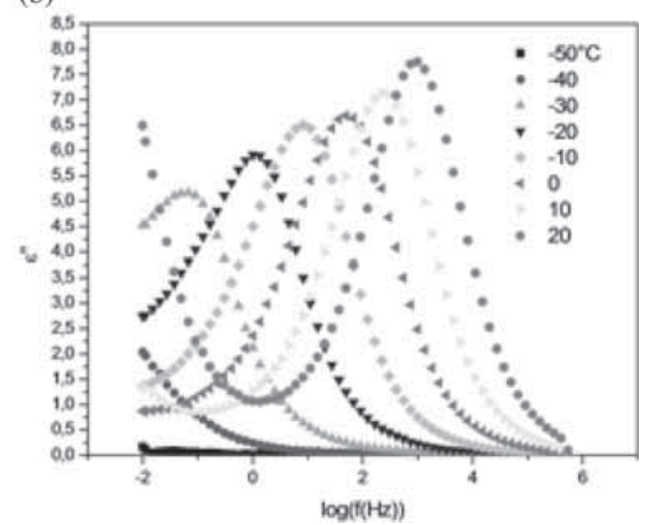

Figure 5. Frequency dependence of (a) permittivity $\varepsilon^{\prime}(\omega)$ and (b) dielectric loss $\varepsilon^{\prime \prime}(\omega)$ for $\left(\left[\mathrm{M}\left(\mathrm{CH}_{2}\right) \mathrm{IM}^{2+}\right]\left[2 \mathrm{NTf}_{2}^{-}\right]\right)$at various temperatures.

at $f_{\mathrm{c}}=\left(\omega_{\mathrm{c}} / 2 \pi\right)$, where $f_{\mathrm{c}}$ is the critical frequency. It is clear that the value of $\varepsilon$ increases with the increase of temperature and decreases with the increase of frequency. The rate of the increase by temperature is faster at higher temperatures and the rate of decrease by increasing frequency is faster at lower frequencies. The high value of permittivity at low frequencies is attributed to the electrode polarization phenomenon occurring as a result of an accumulation of ions near the electrodes [22,23].

This behaviour is also observed in other ionic liquids [24-26]. The behaviour of $\varepsilon$ at different temperatures can be explained by means of the dielectric polarization mechanism of the ionic liquids [27]. At low temperatures, the charge carriers which in most cases have lower thermal energy cannot orient themselves with respect to the direction of the applied field; therefore, they possess a weak contribution to the polarization and to the real part of the dielectric constant.

On the other hand, at high frequencies in the $10^{6}-10^{5} \mathrm{~Hz}$ range, we find $\varepsilon^{\prime}(f) \equiv \varepsilon^{\prime}(\infty) \approx 16$, which is a typical highfrequency permittivity value, also observed for many ionic liquids and glasses [28].

Finally, as the temperature increases, the charge carriers get an amount of thermal excitation energy, so that they are able to respond to the change in the external field more easily at low frequencies. Gradually, their contribution to the polarization leading to an increase of the real part of the dielectric constant.

This result perfectly agrees with the observation previously reported in the literature about the increase in the frequency, in this case, the dipoles will no longer be able to rotate sufficiently rapidly, so their oscillation will begin to lag behind this field, which explains the observed decrease in $\varepsilon$ with frequency [29,30].

As previously stated, our di-cationic ionic liquid, containing a central cationic unit capped by a basic functionality (methylidene alkyl chain between two imidazolium rings and has a radical methyl), and a spacer of the anion was designed to be flexible, shows a great structural symmetry. It may be remarked here that this structure chain and its rotation in phase transition phase should be more shifted towards higher frequency. However, at temperatures ranging from -30 to $20^{\circ} \mathrm{C}$, the di-cationic ionic liquid chain becomes flexible and shows relaxation peaks whose frequency increases with temperature, which indicates that the relaxation phenomena is thermally activated.

\section{Conclusion}

Crystal structure, thermal and dielectric studies of bis-methyl imidazolium methylidene bis(trifluorométhanesulfonyl)imide have been investigated. The compound crystallizes at room temperature in monoclinic system with space group: $\mathrm{P} 21 / \mathrm{c}$. The variation of the real and imaginary parts of the dielectric constant as a function of temperature and frequency was discussed on the basis of polarization mechanism in IL. Furthermore, the dielectric constant of IL was found to be decreased with increasing frequency but increased with increasing temperature. Further, the rise in $\varepsilon^{\prime}$, observed at low frequency and high temperature, is mainly due to electrode polarization. The peaks of dielectric loss $\varepsilon^{\prime \prime}$ shifts towards higher frequency with increasing temperature, which indicates that the relaxation phenomenon of the charge carrier is thermally activated.

To sum up, this di-cationic ionic liquid can be a potential candidate used in electrochemical devices or other applications because of their good thermal stability.

\section{Electronic supplementary material}

Supplementary material pertaining to this article is available on the Bulletin of Materials Science website (www.ias.ac.in/ matersci). 


\section{Acknowledgements}

We gratefully acknowledge financial support from the National Exceptional Programme (PNE, Algeria), and the 'Ministère de la Recherche et des Nouvelles Technologies', CNRS (Centre National de la Recherche Scientifique), the 'Région Basse-Normandie' and the European Union (FEDER funding). We also acknowledge the financial support of the French Agence Nationale de la Recherche (ANR), through the programme 'Investissements d'Avenir' (ANR10-LABX-09-01), LabEx EMC ${ }^{3}$.

\section{References}

[1] Welton T 1999 Chem. Rev. 992071

[2] Kim J Y, Kim T H, Kim D Y, Park N-G and Ahn K-D 2008 J. Power Sources 175692

[3] Ito K, Nishina N and Ohno H 2000 Electrochim. Acta 451295

[4] Han X and Armstrong D W 2005 Org. Lett. 74205

[5] Zafer C, Ocakoglu K, Ozsoy C and Icli S 2009 Electrochim. Acta $\mathbf{5 4} 5709$

[6] Anderson J L and Armstrong D W 2005 Anal. Chem. 776453

[7] Soukup-Hein R J, Remsburg J W, Dasgupta P K and Armstrong D W 2007 Anal. Chem. 797346

[8] Jin C-M, Ye C, Phillips B S, Zabinski J S, Liu X, Liu W and Jean'ne M S 2006 J. Mater. Chem. 161529

[9] Qi M and Armstrong D W 2007 Anal. Bioanaly. Chem. 388889

[10] Wang J, Wang M, Yang X, Zou W and Chen X 2015 Chinese J. Chem. Eng. 23816

[11] Moumene T, Belarbi E H, Haddad B, Villemin D, Abbas O, Khelifa B and Bresson S 2014 J. Mol. Struct. 106586

[12] Sheldrick G M 1990 SHELXS-97, University of Göttingen, Germany
[13] Sheldrick G M 1997 SHELXL-97, University of Göttingen, Germany

[14] Carvalho T, Augusto V, Rocha Â, Lourenço N M T, Correia N T, Barreiros S et al 2014 J. Phys. Chem. B 118 9445

[15] Clough M T, Geyer K, Hunt P A, Mertes J and Welton T 2013 Phys. Chem. Chem. Phys. 1520480

[16] Fernandez A, Torrecilla J S, García J and Rodríguez F 2007 J. Chem. Eng. Data 521979

[17] Kroon M C, Buijs W, Peters C J and Witkamp G-J 2007 Thermochim. Acta 46540

[18] Forsyth S A, Fröhlich U, Goodrich P, Gunaratne H N, Hardacre C, McKeown A and Seddon K R 2010 New J. Chem. 34723

[19] MacFarlane D R and Seddon K R 2007 Aust. J. Chem. 603

[20] Anderson J L, Ding R, Ellern A and Armstrong D W 2005 J. Am. Chem. Soc. 127593

[21] Fuller J, Breda A C and Carlin R T 1998 J. Electroanal. Chem. 45929

[22] Sangoro J R, Iacob C, Serghei A, Friedrich C and Kremer F 2009 Phys. Chem. Chem. Phys. 11913

[23] Sangoro J R, Serghei A, Naumov S, Galvosas P, Kärger J, Wespe C et al 2008 Phys. Rev. E 77051202

[24] Hunger J, Stoppa A, Schrödle S, Hefter G and Buchner R 2009 Chem. Phys. Chem. 10723

[25] Daguenet C, Dyson P J, Krossing I, Oleinikova A, Slattery J, Wakai C et al 2006 J. Phys. Chem. B 11012682

[26] Stoppa A, Hunger J, Buchner R, Hefter G, Thoman A and Helm H 2008 J. Phys. Chem. B 1124854

[27] Saroj A L and Singh R K 2012 J. Phys. Chem. Solids 73162

[28] Hyde J M and Tomozawa M 1989 J. Non-Cryst. Solids 10918

[29] Sangoro J R and Kremer F 2011 Ac. Chem. Res. 45525

[30] Krause C, Sangoro J R, Iacob C and Kremer F 2009 J. Phys. Chem. B 114382 